\title{
A NoÇÃo DE DAS DING EM JaCQUes LaCAN
}

\author{
Ariana Lucero*
}

\section{Resumo}

O presente artigo visa explicitar como se deu a apropriação lacaniana da noção de das Ding a partir do Projeto de uma psicologia de Freud ([1895] 1995). Além disso, buscaremos mostrar em que medida das Ding pode esclarecer aspectos importantes da obra de Lacan como, por exemplo, a relação do infante com o Outro, bem como o estatuto deste último; e a questão da tradução do termo Vorstellungsrepräsentanz por representante-darepresentação.

Palavras-chave: das Ding; Lacan; Projeto; Outro; Vorstellungsrepräsentanz.

\section{ABSTRACT}

The notion of Das Ding In JacQues Lacan

The present article aims to explicit the Lacanian usage of the notion of das Ding extracted from Freud's ([1895] 1995) Entwurf einer Psychologie. We will also try to show at what point das Ding can clarify important aspects of Lacan's work, such as the relationship of the infant with the Other, as well as the statute of the latter; and the question of the translation of the term Vorstellungsrepräsentanz to presentation-of-representation.

Keywords: das Ding; Lacan; Entwurf; Other; Vorstellungsrepräsentanz.

O psicanalista francês Jacques Lacan buscou a noção de das Ding no texto freudiano do "Projeto de uma psicologia" (Freud, [1895] 1995). Ele afirma que muitos leitores, especialmente aqueles que conservam o espírito crítico, podem questionar a legitimidade de sua apropriação do conceito freudiano de das Ding, pensando se tratar apenas de um pequeno detalhe que ele foi "pescar" no "Proje-

* Psicóloga; Mestranda do Programa de Pós-graduação em Psicologia da Universidade Federal de Minas Gerais (UFMG); Bolsista do CNPq. 
to...”. No entanto, Lacan acredita que nos textos de Freud nada é "caduco" (Lacan, [1959-1960] 1997: 128), nem pode ser descartado, sendo necessário perceber e desenvolver os pontos que permaneceram abertos, hiantes. É nesse sentido que ele assume plena responsabilidade por "das Ding" (Lacan, [1959-1960] 1997: 127128).

Acompanhando Lacan, devemos buscar as origens e o desenvolvimento da noção de das Ding em Freud, mas sem esquecer de sua advertência: não se trata de simplesmente sermos fiéis ao texto freudiano e fazermos sua exegese "como se aí estivesse a fonte de uma verdade ne varietur que seria o modelo, o leito, a vestimenta a impor a toda a nossa experiência" (Lacan, [1959-1960] 1997: 51).

No "Projeto...", Freud ([1895] 1995) descreve o aparelho psíquico a partir da diferenciação de três grupos de neurônios - $\Phi, \Psi$ e $\omega$ - responsáveis pela percepção, memória e consciência, respectivamente. $O$ sistema $\Psi$ se divide em: sistema $\Psi$ núcleo, que recebe diretamente os estímulos endógenos; e sistema $\Psi$ manto, que recebe as informações do mundo externo a partir de $\Phi$.

O aparelho descrito por Freud ([1895] 1995) se apoia na noção de quantidade (Q), entendida como o que diferencia atividade e repouso. A tendência do organismo seria a de manter inalterada essa diferença entre atividade e repouso, de modo que ele aspira a libertar-se de Q. Esse é o princípio de inércia, que justifica a existência do movimento reflexo: qualquer aumento na quantidade ocasionada por um estímulo externo deve ser eliminado pela via da ação motora, pois seria sentido como desprazer. Já o prazer adviria da sensação de eliminação de Q. O princípio de prazer é um dos princípios que regem o funcionamento mental e tem por objetivo evitar o desprazer e proporcionar prazer.

Todavia, o psicanalista vienense percebe que as quantidades endógenas não cessam nunca, o que constitui a verdadeira "mola pulsional do mecanismo psíquico" (Freud, [1895] 1995: 30). O organismo não pode se livrar dele mesmo e esse é o problema colocado pela vivência de satisfação ${ }^{1}$. Freud nota que, quando o bebê sente fome, a resposta do organismo se dirige a um esforço de eliminação, que se verifica na forma do grito ou do choro; mas estes não logram êxito em diminuir a tensão em $\Psi$. É preciso uma intervenção que, por um certo tempo, remova no interior do corpo a liberação de quantidades, e uma intervenção dessa ordem requer uma alteração no mundo externo (como a provisão de alimento, no caso da fome), que, enquanto ação específica, só pode se efetuar a partir de determinados caminhos.

O organismo humano é, a princípio, incapaz de promover essa ação específica. Ela se efetua por ajuda alheia, quando a atenção de um outro é atraída pelo grito do bebê. A descarga motora, ocasionada pela alteração interna, é originariamente 
a única via de eliminação possível. O grito adquire, assim, a função de comunicação, na medida em que um outro ser humano pode interpretá-lo como apelo e como demanda a ser respondida. De onde o famoso adágio freudiano: "o desamparo inicial do ser humano é a fonte originária de todos os motivos morais” (Freud, [1895] 1995: 32).

Quando a ação específica se efetiva, o organismo deve executar imediatamente no interior de seu corpo, por meio de dispositivos reflexos, a atividade necessária para remover o estímulo endógeno. A totalidade do evento resulta em uma vivência de satisfação, que possui duas consequências essenciais:

1) produz-se no manto a ocupação dos neurônios $(\alpha)$ que correspondem à percepção do objeto ("pessoa prestativa"), estabelecendo-se uma facilitação entre essas ocupações e os neurônios nucleares;

2) em outros neurônios do manto $(\beta)$ chegam as notícias de eliminação, sentidas como prazer $(\omega)$, devido ao movimento reflexo desencadeado após a ação específica. Estas notícias realizam-se porque todo movimento, através de suas consequências laterais, dá lugar a novas excitaçôes sensoriais (provenientes da pele e dos músculos) que produzem em $\Psi$ uma imagem de movimento.

A formação das facilitações (Bahnungen) nos permite uma compreensão mais ampla do desenvolvimento de $\Psi$. Não só se estabelece uma facilitação entre os neurônios $\Psi$ do núcleo e os neurônios $\Psi$ do manto, como os próprios neurônios $\Psi$ do manto estabelecerão facilitações entre si. Se os neurônios $\alpha$ e $\beta$ de $\Psi$ do manto forem ocupados simultaneamente, a ocupação quantitativa de $\alpha$ passa para o neurônio $\beta$, resultando em uma barreira de contato facilitada entre $\alpha-\beta$. A lei de associação por simultaneidade constitui o fundamento das ligações entre os neurônios $\Psi$ (Freud, [1895] 1995).

Assim, como resultado da vivência de satisfação, origina-se uma facilitação entre as duas imagens recordativas (percepção do objeto $(\alpha)$ e imagem de movimento $(\beta)$ e entre elas e os neurônios nucleares. Com o reaparecimento do estado de urgência ou de desejo, a ocupação prossegue dos neurônios $\Psi$ do núcleo para as duas recordações, reativando-as. A imagem recordativa do objeto é a primeira a ser afetada pela ativação do desejo, o que ocasiona algo idêntico a uma percepção, equivalente a uma alucinação. Se, em consequência disso, uma ação reflexa for iniciada, o processo acabará em desilusão, uma vez que a satisfação não será possível (Freud, [1895] 1995).

A criação das facilitações faz com que as quantidades percorram sempre determinados trilhamentos (Bahnungen). O que garante a manutenção desses caminhos é a ocupação constante dos neurônios. Num primeiro momento, hipotetica- 
mente, o aparelho psíquico podia eliminar as Qs, conservando-se sem estímulos princípio de inércia. Entretanto, a necessidade vital, impelida pela pulsão, obriga o organismo a um armazenamento de $\mathrm{Q}$, que lhe permita não somente conservar os caminhos de descarga (eliminação), mas também atentar ${ }^{2}$ para o mundo externo, buscando a ação específica que garanta a satisfação. É a atenção que caracteriza o "estado de expectativa" (Freud, [1895] 1995: 76).

Freud ([1895] 1995) propõe que chamemos a totalidade das ocupações em $\Psi$ de $E$ u, do qual pode-se separar uma parte permanente - núcleo - de uma variável, o manto. $\mathrm{O}$ eu é responsável por impedir processos psíquicos primários através de ocupações laterais. Estas impedem que a imagem recordativa do objeto seja abundantemente ocupada, o que resultaria em uma alucinação. Nestes casos, a ocupação de desejo não é tão intensa a ponto de iniciar uma eliminação, de tal forma que apenas uma percepção externa real teria quantidade suficiente para ativar esse circuito.

É a inibição (Freud, [1895] 1995) do eu que possibilita um critério de diferenciação entre percepção e recordação, mas este mecanismo pode falhar se o objeto de desejo for ocupado com abundância.

Segundo Freud ([1895] 1995), a experiência biológica ensinará o organismo a não ocupar as imagens recordativas desejadas acima de certa medida e a não iniciar a eliminação antes do aparecimento de um signo de realidade. Ora, mas o signo de realidade é definido como a própria notícia de eliminação $(\beta)$, de modo que ele será útil para chamar a atenção de $\Psi$ para uma percepção, ou para a ausência da mesma.

O psicanalista afirma que, raramente, uma nova percepção coincide totalmente com a recordação, sendo a identidade exata entre elas uma situação hipotética, impossível na vida real, e mesmo disfuncional, já que dispensaria a função do juízo. Vejamos como Freud ([1895] 1995) exemplifica essa situação:

1) a ocupação de desejo é formada pelo neurônio $a+$ neurônio $b$;

2) a ocupação de percepção é formada pelo neurônio $a+$ neurônio $c$.

Uma vez que na perspectiva freudiana do "Projeto..." (Freud, [1895] 1995) é inseguro iniciar a eliminação enquanto os signos de realidade não concordarem com a totalidade da ocupação de desejo, o complexo perceptivo deve decomporse em:

1) um componente neurônio $a$, que quase nunca muda e que passará a se chamar "a coisa" (das Ding);

2) um componente neurônio $b$, que quase sempre varia e se chamará seu predicado, sua atividade ou atributo. 
Nesse ponto, Freud ([1895] 1995) destaca a semelhança entre o núcleo do eu e a componente constante da percepção em $\Psi$ do manto (das Ding); e entre as ocupaçôes mutáveis do manto e a componente inconstante.

É interessante notar que, apesar de se referir ao componente perceptivo, o que Freud ([1895] 1995) decompõe é a ocupação de desejo. Algumas linhas à frente, ele mostra que, na verdade, é a partir do neurônio $c$ que será perseguida a identidade para reencontrar o neurônio $b$. Em geral, o que se intercala entre o neurônio $c$ e o neurônio $b$ é uma imagem de movimento que advém de uma notícia de eliminação, o que nos leva a pensar que o neurônio $a$ seja a percepção do objeto.

Vejamos como isso pode ser ilustrado pelo esquema abaixo:

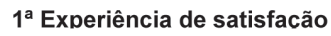

\section{Núcleo Manto}
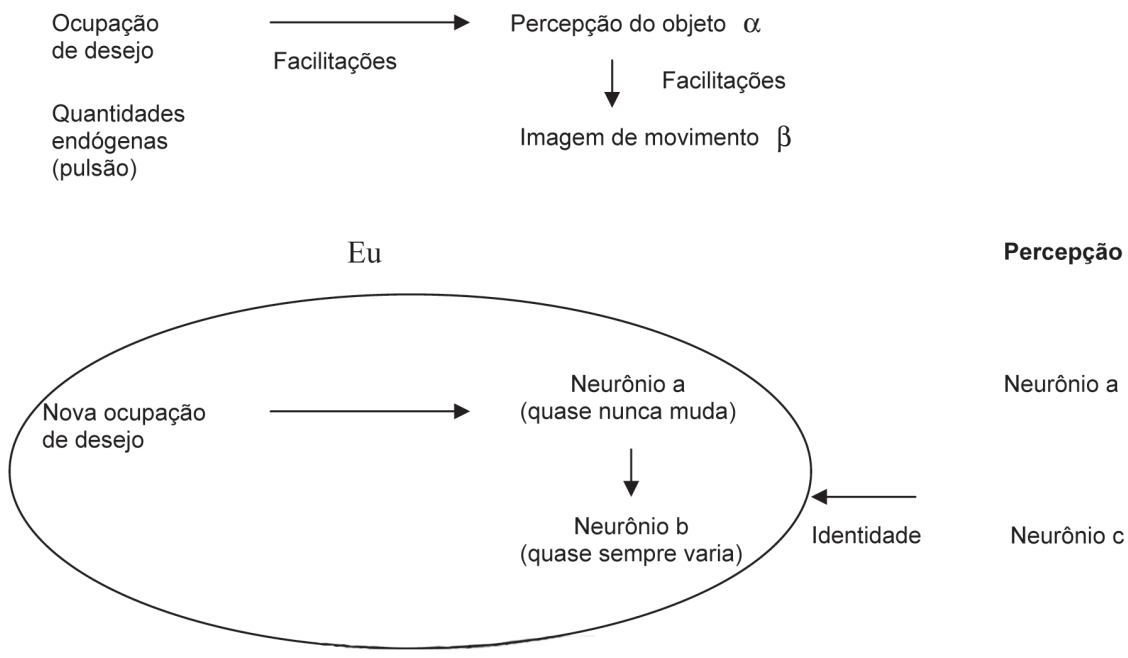

Figura $1-\mathrm{A} 1^{\text {a }}$ experiência de satisfação

Pois bem, pode-se concluir do exposto que, independentemente do objeto percebido, o aparelho psíquico perseguirá a imagem de movimento que corresponde ao prazer proporcionado pela vivência de satisfação. Freud ([1895] 1995) ressalta que o fundamento da existência do julgar está nas experiências corporais, sensações e imagens de movimento. O que é bem descrito pela seguinte afirmação de Patrícia Porchat (2005): 
$\mathrm{Na}$ medida em que não há uma correspondência absoluta entre o objeto percepcionado e o objeto de desejo, o que garante o término da busca pelo objeto que proporciona satisfação é a interrupção do processo de somação (da fome, no exemplo de Freud), a representação de uma sensaçãao corporal. [...] Freud considera como último elemento do circuito desiderativo a representação de uma sensação corporal (de prazer) que indica a interrupção do processo de somação (Porchat, 2005: 136).

Ainda a esse respeito, Moustapha Safouan (1988) nos oferece uma preciosa explicação:

a pressão das necessidades conduz não a pensar a coisa (seja ela o seio ou o Nebenmensch) que restabelecia o repouso, ou a desejá-la, mas sim a crer percebê$l a$, dito de outro modo, a aluciná-la. Lidamos, então, não apenas com um organismo pouco preparado para a vida, como o admitiria qualquer biólogo e qualquer observador da primeira infância, mas ainda, e sobretudo, com um psiquismo positivamente dotado de um princípio contrário às exigências da vida como tal, porquanto esta requer uma adesão mínima aos sinais ou, se quisermos, aos logros do Umwelt. No momento em que supomos que o aparelho psíquico não se contenta em pensar o que quer, mas "realiza" seu pensamento antes de reconhecê-lo no real, colocamos, ao mesmo tempo, que esse aparelho existe em uma adesão principal às suas próprias ficçóes ou aos seus próprios logros; um aparelho, em suma, que não tem necessidade de se opor para se pôr, um aparetho que não espera, que não espera nem mesmo que a realidade o decepcione antes de substitui-la alucinatoriamente por uma outra realidade (Safouan, 1988: 28; grifos nossos).

\section{DAS DING E O OUTRO}

Freud ([1895] 1995) também supõe a situação em que um outro, um próximo, seja o objeto da percepção do sujeito. Este objeto interessa porque é, ao mesmo tempo, o primeiro objeto de satisfação, o primeiro objeto hostil ${ }^{3}$ e o único poder auxiliar. Mesmo sendo semelhante ao sujeito, o complexo perceptivo do outro se decompóe em dois elementos:

1) um dos quais impressiona por uma estrutura constante e permanece reunido como Coisa (das Ding) - é inassimilável;

2) enquanto o outro é compreendido através do trabalho recordativo, ou seja, enquanto pode ser rastreado até uma notícia do próprio corpo. 
Essa indicação é suficiente para nos esclarecer que o outro que responde aos apelos do recém-nascido não é um outro identificado por ele como semelhante, mas um sujeito que possui um traço diferencial - está submetido à ordem simbólica. A experiência de satisfação depende inteiramente desse Outro e, nesse ponto, Lacan nos adverte que o princípio de realidade não tem somente a função de regular o princípio de prazer, mas é o que o articula e o faz existir: "O prazer não se articula na economia humana senão numa relação com esse ponto, certamente deixado vazio, enigmático, mas que apresenta uma certa relação com o que é para o homem a realidade" (Lacan, [1959-1960] 1997: 54).

A primeira apreensão da realidade pelo sujeito se dá pelo Outro que articula o "à-parte e a similitude, a separação e a identidade" (Lacan, [1959-1960] 1997: 68). Pela ilustração acima, pudemos constatar que das Ding é comum tanto aos investimentos do manto como aos do núcleo, sem ser, no entanto, redutível a um ou a outro. Ela é uma estrutura constante, presente no estado de desejo e na percepção, mas sem pertencer propriamente a nenhum dos dois; das Ding se localizaria na interseção vazia de dois conjuntos separados (Dreyfuss, citado por Garcia-Roza, 1991).

Para Lacan, das Ding é o elemento que é originalmente isolado pelo sujeito em sua experiência do Outro como sendo, por sua natureza, estranho (Fremde): "O Ding como Fremde, estranho e podendo mesmo ser hostil num dado momento, em todo caso como o primeiro exterior, é em torno do que se orienta todo o encaminhamento do sujeito" (Lacan, [1959-1960] 1997: 69).

Apesar de ser inassimilável, das Ding serve de referência para o desejo, na medida em que permite ao aparelho atentar para o mundo das percepçôes. Das Ding enquanto vazio, furo na subjetividade, funciona como índice de exterioridade. É algo interno à subjetividade que funciona como índice da realidade.

No texto de 1925, "A negativa”, Freud ([1925] 2007) nos diz que a função do juízo é saber se algo que está disponível na forma de uma representação psíquica no eu pode ser reencontrado também na esfera da realidade. Ele nos lembra que todas as representações mentais se originaram de percepções, de modo que, a princípio, a própria existência de uma representação já seria uma garantia de sua realidade. A oposição entre o subjetivo e o objetivo só se estabelece porque o aparelho psíquico presentifica a percepção do objeto (alucina) sem que ele esteja efetivamente presente no mundo externo, o que, como vimos, resulta em desprazer. Dessa maneira, o objetivo do juízo - nesse artigo chamado teste de realidade - não é encontrar na percepção um objeto correspondente à recordação, mas reencontrálo, certificar-se de que ele ainda permanece presente. Por fim, Freud acrescenta 
que "o teste de realidade só entrará em cena quando e se os objetos, que outrora trouxeram satisfação, já tiverem sido perdidos" (Freud, [1925] 2007: 149).

Segundo Lacan, o objeto que se almeja reencontrar é das Ding, como "Outro absoluto do sujeito" (Lacan, [1959-1960] 1997: 69). O problema é que este objeto é, desde o início, perdido: trata-se de reaver o que não pode ser reencontrado. Deparamo-nos com suas coordenadas de prazer; o que é buscado é o objeto em relação ao qual o princípio de prazer funciona: "Todos os ataques de tonteiras e acessos de choro visam a uma outra pessoa - mas, basicamente, visam àquela outra pessoa pré-histórica e inesquecível, que jamais é igualada por ninguém posteriormente" (Freud, [1887-1904] 1986: 213).

O objetivo da ação específica - e, segundo Freud ([1887-1904] 1986), de toda ação - é ser um meio de reprodução do prazer. Trata-se sempre de reproduzir o estado inicial, de reencontrar das Ding.

Lacan ([1959-1960] 1997) propõe que tomemos das Ding como o que é, originalmente, fora-do-significado. É em torno dela que se organizam as representações. Estas dependem das qualidades, ou atributos, do objeto, de tal forma que deve ficar claro que o movimento sempre parte dos predicados ou das propriedades, ou seja, da parte variável (neurônios $b, c, d .$. ), e nunca da parte que permanece idêntica. É em função dos neurônios que variam que poderão ser feitas as comparações entre os vários complexos que apresentam um ponto de interseção $a$.

\section{DAs Ding E AS VORSTELLUNGSREPRÄSENTANZ}

$\mathrm{Na}$ orientação ao objeto dada por das Ding, as representações atraem-se uma à outra segundo as leis de uma organização de memória - das facilitações (Bahnungen), cujo funcionamento é regulado pelo princípio de prazer. Lacan sugere que a melhor tradução para Bahnung seria "trilhamento", que remete também à concatenação, associação, ou cadeia significante (Lacan, [1959-1960] 1997: 53).

O psicanalista assevera que "é entre percepção e consciência que aquilo que funciona no nível do princípio do prazer se insere" (Lacan, [1959-1960] 1997: 80). Para entender essa colocação é preciso retroceder ao esquema de Freud, presente na "Carta 52", de 6 de dezembro de 1896 (Freud, [1887-1904] 1986):

$$
\begin{array}{ccccc} 
& \text { I } & \text { II } & \text { III } & \\
\text { W } & \text { Wz } & \text { Ub } & \text { Vb } & \text { Bew }
\end{array}
$$


W [Wahrnehmungen (percepções)]: neurônios em que se originam as percepções, às quais a consciência se liga, mas que não retêm nenhum traço do que aconteceu; correspondem aos neurônios $\varphi$ do Projeto.

Wz [Warnehmungszeichen (indícios de percepção)]: primeiro registro das percepções, organizado de acordo com associaçōes por simultaneidade.

$\mathrm{Ub}$ [Unbewusstsein (inconsciência)]: segundo registro, disposto de acordo com relações, talvez causais. Os traços Ub correspondem a lembranças conceituais.

$\mathrm{Vb}$ [Vorbewusstsein (pré-consciência)]: terceiro registro, ligado à representação-de-palavra.

Bew [Bewusstsein (consciência)]: neurônios perceptivos e desprovidos de memória; correspondem aos neurônios ù do Projeto.

Pois bem, entre percepção e consciência temos o funcionamento do aparelho psíquico - ou de memória $(\Psi)$ - formulado por Freud. Apesar de ter sido primeiramente elaborado em 1896, esse esquema estará presente, de maneira implícita, na última parte de seu artigo de 1915, "O inconsciente" (Freud, [1915] 2006). Neste escrito, Freud sugere que separemos a representação-de-objeto, isto é, a ideia consciente que temos do objeto, em representação-de-palavra e representação-de-coisa. Se tomarmos o modelo da "Carta 52", estas correspondem às lembranças conceituais situadas no registro $U b$, ou inconsciência.

Lacan ([1959-1960] 1997) destaca que a Coisa (das Ding) é diferente da representação-de-coisa (Sachvortellung). A Sachvorstellung corresponde a Vorstellungsrepräsentanz, ou a gravitação das Vorstellungen em torno de das Ding, e pode se tornar consciente ao se ligar a uma Wortvorstellung (representação-depalavra). É válido lembrar que a representação-de-coisa é um complexo associativo composto pelas mais variadas representaçōes visuais, acústicas, táteis, cinestésicas etc. Ela não é uma representação fechada ou passível de fechamento.

Para entender a sutileza da nomenclatura lacaniana, é preciso conceber que algo se instala no lugar da Coisa, fazendo com que ela se apague, ao mesmo tempo que garante a sua existência, por significá-la. Isso que aparece para organizar a "realidade muda" (Lacan, [1959-1960] 1997: 72) de das Ding é o significante. Lacan nos lembra que:

Antes ainda que se estabeleçam relaçōes que sejam propriamente humanas, certas relações já são determinadas. Elas se prendem a tudo que a natureza possa oferecer como suporte, suportes que se dispõem em temas de oposição. A natureza fornece, para dizer o termo, significantes, e esses significantes organizam de modo inaugural as relaçôes humanas, lhes dão as estruturas, e as modelam (Lacan, [1964-1965] 1979: 26). 
Ele dirá que o primeiro sistema com o qual lidamos é o das Wahrnehmungszeichen, os sinais de percepção que se expressam na alternância a partir de uma sincronia fundamental. Estes sinais de presença/ausência, tensão/apaziguamento já são significantes advindos da imersão na ordem simbólica e terão um papel essencial na própria capacidade de alucinação da Coisa. É porque existe um momento, um período, uma constância no aparecimento do Outro que a realidade pode existir - não nos esqueçamos de que o real é aquilo que retorna sempre ao mesmo lugar (Lacan, [1964-1965] 1979).

Se é próprio da natureza nos fornecer significantes, como nos diz Lacan na citação acima, é próprio dos seres de linguagem o tomarem simbolicamente. É a partir de um Outro que tais significantes poderão ser transmitidos para o recémnascido. Ao falar de um real e de um lugar, Lacan busca enfatizar o papel de referência, de orientação, que esse Outro deve ocupar. Assim como na Antiguidade o conhecimento se articulava em torno do que se repetia, do que retornava - o movimento dos astros, as estações do ano -, nos primórdios da constituição psíquica é preciso que algo possa dar alguma garantia da realidade ao bebê. Esse Outro comporta algo de real, enigmático, e não será jamais assimilável, permanecendo "reunido como coisa" (Freud, [1895] 1995: 45), para utilizar uma expressão freudiana.

Essa pequena digressão foi apenas para mostrar como, a partir de um universo simbólico, o real intervém como necessário. Se pensarmos na topologia do nó borromeano, é a passagem do simbólico sobre esse real sob a forma do Nome-dopai que o nomeará como Coisa. O Nome-do-pai é o significante que transmite a lei do incesto, impedindo o acesso à Coisa e organizando a cadeia significante.

Nesse sentido, as representações (Vorstellungen) que gravitam em torno da Coisa são sempre Vorstellungsrepräsentanz, uma vez que o mundo das representações será, desde então, organizado segundo as possibilidades do significante. Citamos Lacan:

Em outros termos, é na medida em que a estrutura significante interpõe-se entre a percepção e a consciência que o inconsciente intervém, não mais enquanto Gleichbesetzung, função da manutenção de um certo investimento, mas na medida em que ele concerne às Bahnungen. A estrutura da experiência acumulada reside aí e permanece aí inscrita (Lacan, [1959-1960] 1997: 67).

Garcia-Roza (1991) afirma que o sentido de uma Vorstellung não decorre daquilo ao qual ela supostamente se refere, mas da relação que ela mantém com as outras Vorstellungen. Afinal, essa relação é arbitrária e regida, primeiramente, pela 
lei de das Ding, que busca o prazer e a identidade entre coisas que, aparentemente, não têm relação nenhuma. A representação-de-coisa só adquire sua significação pela articulação com a representação-de-palavra, de maneira que é apenas a posteriori que podemos observar a evolução que os esquemas apresentam em dimensão cronológica.

Com efeito, a função da representação é aquilo que melhor define o significante (Thomas-Quilichini, 2004).

Nossa definição do significante (não existe outra) é: um significante é aquilo que representa o sujeito para outro significante. Esse significante, portanto, será aquele para o qual todos os outros significantes representam o sujeito: ou seja, na falta desse significante, todos os demais não representariam nada. Já que nada é representado senão para algo (Lacan, [1960] 1998: 833).

Um significante não representa a si próprio: "uma definição coerente não pode atribuir ao significante um significado, mas deve apenas e tão-somente descrever uma relação - relação esta fundada no princípio da diferença” (Iannini, 2000: 81), tal como dito acima.

As representaçõos (Vorstellungen) têm uma organização significante (ThomasQulichini, 2004), mas são as Vorstellungsrepräsentanz que equivalem à noção e ao termo significante ${ }^{4}$. A tradução proposta por Lacan para o termo Vorstellungsrepräsentanz não é a mais fiel à gramática alemã. No Vocabulário da Psicanálise, Laplanche e Pontalis (2004) adotam o termo "representante-representação", mas Lacan opta por "representante da representação" para enfatizar o papel do significante Nome-do-pai na organização das representaçôes.

Se uma representação remete a outra, não sendo passível de ser representada, um "representante da representação" demarca o vazio no lugar de das Ding, sem conseguir preenchê-lo ou traduzi-lo; ao mesmo tempo, é capaz de reunir as representações (Vorstellungen) que representam os atributos da Coisa.

É sempre válido ressaltar que das Ding está além do sistema das Vorstellungsrepräsentanz; ela não é significante. É aquilo com que se lida da maneira menos operacional:

Digamos, hoje, que, se ela [das Ding] ocupa esse lugar na constituição psíquica que Freud definiu sobre a base temática do princípio do prazer, é que ela é, essa Coisa, o que do real - entendam aqui um real que não temos ainda que limitar, o real em sua totalidade, tanto o real que é o do sujeito, quanto o real com o qual ele lida como lhe sendo exterior - o que, do real primordial, padece do significante (Lacan, [1959-1960] 1997: 149 - grifos nossos). 
A Coisa, como real, insiste, persiste e retorna, não sendo jamais representada ou articulada em uma cadeia significante.

\section{REFERÊNCIAS BIBLIOGRÁFICAS}

Freud, S. (1887-1904). A correspondência completa de Sigmund Freud para Wilhelm Fliess. Rio de Janeiro: Imago, 1986.

. (1895). Projeto de uma psicologia. Rio de Janeiro: Imago, 1995.

. (1915). O inconsciente. In: Escritos sobre a psicologia do inconsciente, v. II (pp.

13-74). Rio de Janeiro: Imago, 2006.

. (1925/2007). A negativa. In: Escritos sobre a psicologia do inconsciente, v. III (pp. 145-157). Rio de Janeiro: Imago.

Garcia-Roza, L. A. (1991). Introdução à metapsicologia freudiana, v. I. Rio de Janeiro: Jorge Zahar.

Iannini, G. (2000). Cartografias de um desencontro: estrutura e sujeito em Jacques Lacan. In: Teixeira, A. \& Massara, G. Dez encontros: psicanálise e filosofia-o futuro de um malestar (pp. 73-82). Belo Horizonte: Opera Prima.

Lacan, J. (1958-1959). Seminário 6, O desejo e sua interpretação. Inédito.

- (1959-1960). Seminário 7, A ética da psicanálise. Rio de Janeiro: Jorge Zahar, 1997.

- (1960). Subversão do sujeito e dialética do desejo no inconsciente freudiano. In: Escritos (pp. 807-842). Rio de Janeiro: Jorge Zahar, 1998.

. (1964-1965). Seminário 11, Os quatro conceitos fundamentais da psicanálise.

Rio de Janeiro: Jorge Zahar, 1979.

Laplanche, J. \& Pontalis, J.-B. (2004). Vocabulário da psicanálise. São Paulo: Martins Fontes.

Porchat, P. (2005). Freud e o teste de realidade. São Paulo: Casa do Psicólogo/Fapesp.

Safouan, M. (1988). O fracasso do princípio do prazer. Campinas: Papirus.

Thomas-Quilichini, J. (2004). O conceito de representação. In: Dicionário de psicanáliseFreud e Lacan, v. II (pp. 110-125). Salvador: Ágalma.

\section{NoTAS}

1 A vivência de satisfação encontra-se descrita no "item 11" da "Parte I - Plano Geral do Projeto" do "Projeto...” (Freud, [1895] 1995: 31-33). 
2 Ver o Seminário 7, A ética da psicanálise, onde Lacan ([1959-1960] 1997: 69) coloca: "O mundo das percepções nos é dado por Freud como que dependendo dessa alucinação fundamental sem a qual não haveria nenhuma atenção disponível”.

3 Assim como o bebê precisa da ajuda alheia para se alimentar, precisa dela para aplacar a dor, provocada pelos estímulos do ambiente, de modo que o outro também é o primeiro objeto hostil, pois aparece como uma das facilitações resultantes dessa experiência. Esse também é um dos motivos pelos quais o acesso ao objeto deve ser impedido - defesa primária.

4 De acordo com Josiane Thomas-Quilichini (2004), autora do verbete "O conceito de representação" do Dicionário de psicanálise - Freud e Lacan, na lição de 26/11/1958 do Seminário 6, O desejo e sua interpretação, Lacan (1958-1959: inédito) teria feito a seguinte afirmação: “esse Vorstellungs-Repräsentanz é estritamente equivalente à noção e ao termo de significante”.

Recebido em 05 de dezembro de 2008 Aceito para publicação em 12 de maio de 2009 